\title{
Solar Cell \\ Array Design Handbook
}

The Principles and Technology of Photovoltaic Energy Conversion 


\title{
Solar Cell \\ Array Design Handbook
}

\section{The Principles and Technology of Photovoltaic Energy Conversion}

\author{
H. S. Rauschenbach \\ Special Assistant for Advanced Technology \\ TRW Defense and Space Systems Group
}




\title{
Van Nostrand Reinhold Company Regional Offices: \\ New York Cincinnati Atlanta Dallas San Francisco \\ Van Nostrand Reinhold Company International Offices: \\ London Toronto Melbourne
}

Copyright $\odot 1980$ by Litton Educational Publishing, Inc.

Softcover reprint of the hardcover 1st edition 1980

Library of Congress Catalog Card Number: 79-9389

ISBN-13: 978-94-011-7917-1

e-ISBN-13: 978-94-011-7915-7

DOI: $10.1007 / 978-94-011-7915-7$

All rights reserved. No part of this work covered by the copyright hereon may be reproduced or used in any form or by any means-graphic, electronic, or mechanical, including photocopying, recording, taping, or information storage and retrieval systems-without permission of the publisher.

Manufactured in the United States of America

Published by Van Nostrand Reinhold Company

135 West 50th Street, New York. N.Y. 10020

Published simultaneously in Canada by Van Nostrand Reinhold Ltd.

1514131211109876654321

\section{Library of Congress Cataloging in Publication Data}

\author{
Rauschenbach, Hans $\mathrm{S}$ \\ Solar cell array design handbook. \\ Includes index. \\ 1. Solar batteries. 2. Photovoltaic power \\ generation. I. Title.
}




\section{Preface}

Solar cells and solar cell arrays-photovoltaic converters of solar energy into electric energyare a reality. In a time period of two decades, solar cell arrays have grown in size from less than 1 watt to hundreds of kilowatts of electrical output in terrestrial applications and to over 10 kilowatts of output in space. New designs are on the drawing boards and in development laboratories all over the world for terrestrial and space arrays having hundreds and thousands of kilowatts of electric power output. Solar cell efficiency has increased from just a feeble response to sunlight to nearly $20 \%$, surpassing the luminous efficiency of the incandescent light bulb on the way. Solar cell array costs are decreasing rapidly, making photovoltaic electric energy affordable and competitive today in remote areas.

In the same two-decade time span, the solar cell array design effort has matured from a spirited pioneering effort into a sophisticated, sys- tematized, computer-aided process. While it has not been possible to adequately define or improve, or otherwise influence the creative design activity, all other aspects of the design process have been formalized and, for good reason, subjected to documentation, control, and verification.

As the 1970's draw to a close, we find ourselves engulfed by flurrying activities in photovoltaics. While we stand at the threshold of an unprecedented economical exploitation of this particular solar energy conversion technology, we should also realize that all the "easy" inventions have perhaps been made already. From here on, the going can be expected to get tougher. It is hoped that this book will be helpful to those who are going to keep on working for the benefit to all of use who consume energy.

Hans S. Rauschenbach 


\section{Purpose and Scope of this Handbook}

This handbook intends to diseminate as much current and practical information relating to photovoltaic energy conversion technology for earth and space applications as practical. The emphasis is on the presentation of many different concepts and detailed techniques for several reasons:

- To introduce non-technical persons to the subject

- To aid students of the subject and younger workers in this field in mastering it

- To help specialists already working in the field to get their jobs done more effectively

- To inspire the creativity of advanced designers

- To document those concepts, data, and information that are of interest today but are not readily available in the open literature

- To define the entire field of solar cell array design and its multidisciplinary nature.

This handbook is written on several levels, ranging from the illustrative and introductory to the detailed technical. Most of the text should be understandable to advanced high school students and senior technicians. Few sections, if any, are expected to pose difficulties for college graduates or practicing engineers.

The mathematical treatment has been held simple. Differential and integral equations are used sparingly, but are included to permit computer programming. Most mathematical problems can be handled with today's scientific pocket calculators.

This handbook recounts some of the more important historical events that led to today's advanced solar cell array technology and includes sufficient references for locating more detailed accounts. Subjects that are treated elsewhere and readily available, such as general structural design, heat transfer and thermodynamics, civil engineering, and electrical wiring codes and practices, are not included here. Rather, only the special considerations for solar cell arrays are treated.

\section{LEGAL NOTICE}

This handbook attempts to document the knowledge, data, and information which may be of current significance to solar cell array design. However, it is emphasized that there exists a large number of patents which relate to all aspects of solar cell array design, fabrication, and testing, including solar cells, other materials, processes, components, arrangements, and designs. Some of these patents have been described herein, but many more have not been referred to. The description in this handbook of any component, process, apparatus, material, 
design, composition, or any other feature of any article may fall within a claim of an existing patent. It is not the intent of any of the authors, editors, and publishers of and contributors to this handbook-nor is it the intent of any of the sponsoring or performing organizations involved in the preparation of this or the original handbook-to induce anyone to infringe upon any existing patent. It is the responsibility of the prospective user of any of the information, material, data, and descriptions herein to determine whether such usage constitutes in fringement or noninfrigement of any patent or otherwise legally protected or proprietary right.

Specifically, neither the United States, the National Aeronautics and Space Administration, the California Institute of Technology, the Jet Propulsion Laboratory, nor the TRW Defense and Space Systems Group; nor any of the employees of these organizations; nor the pre- parers, editors, approvers, or publishers of this or the earlier document; nor any other person:

1. Makes any warranty or representation, expressed or implied, with respect to the accuracy, completeness, or usefulness of the information contained in this document, or that the use of any information, apparatus, method, or process disclosed in this document may not infringe upon privately owned rights;

2. Assumes any liabilities with respect to the use of, or for damages resulting from the use of, any information, apparatus, method, or process disclosed in this document;

3. Sanctions, approves or recommends any designs, practices, selections, or procedures contained in this document for a specific purpose, use, or project.

\section{SAFETY NOTICE}

Solar cell assemblies, modules, panels, or arrays are sources of electric power and may, under certain circumstances, constitute a potential hazard. Even under conditions of low ambient lighting, a sufficient number of solar cells connected in series may produce voltages and currents that may cause electrocution. Appropriate safety procedures for handling and installing such assemblies must be used and followed (see also the entries under Safety in the Index).
A larger array, when exposed to bright sunlight and short-circuited with a conductor having inadequate cross-section, may start a fire.

Any solar cell assembly, even in low ambient light, when accidentally short-circuited, may cause a spark that is capable of igniting explosive atmospheres, such as may be found in solvent cleaning operations. 


\section{Acknowledgments}

This handbook is a completely revised, updated, and expanded issue of an earlier, space technology oriented document published in October 1976 and now available as NASA CR-149365 [N77-14193 (Vol. 1) and N77-14194 (Vol. 2)] : Solar Cell Array Design Handbook, from the National Technical Information Service, Springfield, Virginia 22151.

The earlier handbood was prepared by the Power Sources Engineering Department of TRW Defense and Space Systems Group, Space Vehicles Division (author and editor, H. S. Rauschenbach), under Contract No. 953913 with the California Institute of Technology, Jet Propulsion Laboratory, Pasadena, California. The active support in the creation of the original document of E. Cohn at NASA Headquarters, J. V. Goldsmith and R. Josephs at JPL, and the following at TRW is gratefully acknowledged and appreciated:

W. R. Brannian and P. Goldsmith, editing and review; A. Kaplan, material properties, stress and fatigue; R. M. Kurland, mechanical systems and components; W. Luft, solar cell and array technology and analysis; A. N. Munoz-Mellows, thermo-dynamics and heat transfer; H. Riess, electrical systems and array analysis; D. W. Rusta, electrical systems, array and orbital analysis; W. R. Scott, corrosion; R. K. Yasui, array technology and material properties.

Also acknowledged and deeply appreciated are the many contributors to the original manuscript drafts and their extensive reviews by numerous personnel in industry and government, especially by L. Slifer of the NASA Goddard Space Flight Center. The typing and editing of the many drafts by M. J. Gustetto, M. C. Winn, and E. A. Harper of TRW, and by my wife Marianne are also greatly appreciated. A special word of appreciation and thanks goes to my resourceful wife and understanding children, Christian, Isabella, Angelina, and David, who provided a home environment that not only made the preparation of this book possible, but also made it a unique experience.

Credit goes also to the literally thousands of workers who, over the years, have created the large body of photovoltaic knowledge and technology from which this author has drawn, and to the institutions of higher learning, private industry, and government which contributed to it in some indispensable way. Since a book of this nature cannot name them all, and naming of only a few would be highly inequitable, names of individuals and organizations have been deleted entirely, except where essential, from the text. Those included in the references were not selected according to the significance of their work, but rather to provide the researcher with leads for a greater in-depth pursuit of a particular topic. 


\section{Contents}

Preface / v

Purpose and Scope of This Handbook / vii

Legal Notice / vii

Safety Notice / viii

Acknowledgments / ix

\section{PART I SOLAR CELL ARRAYS 1}

\section{Array Systems 3}

Array Concepts / 3

1-1. Arrays and Batteries / 3

1-2. Arrays, Panels, Parts, and Components / 3

1-3. Array Types / 3

1-4. The Array as Part of the Power System / 4

1-5. The Array as a System / 6

1-6. Hybrid Systems / 6

Historical Developments / 6

1-7. History of Terrestrial Arrays / 6

1-8. History of Space Arrays / 8

1-9. The Future of Solar Cell Arrays / 12

Array Applications / 15

1-10. Terrestrial Applications / 15

1-11. Space Applications / 15

1-12. Power from Space / 15

Array Systems Performance / 16

1-13. Array Ratings / 16

1-14. Terrestrial Flat-Plate Arrays / 18

1-15. Terrestrial Concentrator Arrays / 20

1-16. Space Flat-Plate Arrays / 20
1-17. Spinning Space Arrays / 21

1-18. Space Concentrator Arrays / 22

1-19. Space Array Orbital

Performance / 22

\section{Array Analysis 30}

Analytical Concepts / 30

2-1. The Role of Analysis / 30

2-2. Atoms and Electrons / 30

2-3. Electric Charge / 31

2-4. Conductors / 31

2-5. Insulators / 32

2-6. Current / 32

2-7. Electric Field / 33

2-8. Potential and Voltage / 34

2-9. Electrical Circuits / 34

2-10. Sources and Generators / 35

2-11. Current Flow Convection / 35

2-12. Resistance and Resistors / 36

2-13. Ohm's Law / 37

2-14. Power / 38

2-15. Energy / 38

2-16. Capacitance and Capacitors / 38

2-17. Magnetism / 39

2-18. Inductance and Inductors / 40

2-19. AC and DC Current / 40

2-20. Impedance / 40

Circuit Analysis / 41

2-21. Circuit Modelling / 41

2-22. Circuit Simplifications / 43

2-23. Circuit Responses / 45

2-24. Circuit Equations / 45

2-25. Operating Points / 47 
Semiconductors and Solar Cell Models / 48

2-26. Quantum Mechanics / 48

2-27. Semiconductor Materials / 50

2-28. Semiconductor Junctions / 50

2-29. Solar Cell Operation / 51

2-30. Solar Cell Equation / 52

2-31. Solar Cell DC Model / 55

2-32. Distributed Parameter Solar Cell Model / 56

2-33. Analytical Models for Computer Work / 56

2-34. Non-Analytical Computer Models / 59

2-35. Selecting the Proper Model / 60

2-36. Solar Cell AC Model / 60

2-37. Solar Cells in Parallel and Series / 64

2-38. Illuminated Arrays / 65

2-39. Partially Shadowed Cells in Parallel / 67

2-40. Partially Shadowed Cells in Series / 68

2-41. Solar Cell Strings with Shunt Diodes / 69

2-42. Shadowing Factors / 72

2-43. Nonilluminated Array Models / 74

2-44. Blocking Diode Models / 74

2-45. Reverse-Biased Solar Cells / 74

2-46. Power Dissipation in ReverseBiased Solar Cells / 76

Array Performance Prediction / 77

2-47. Array Output Analysis / 77

2-48. Sequence of Shifting $I-V$ Curves / 80

2-49. Calculation of Angle of Incidence / 81

2-50. Calculation of Effective Solar Intensity / 82

2-51. Calculation of Cell and Array $I-V$ Curves / 82

Shadow Analysis / 84

2-52. Shadows / 84

Thermal Analysis / 89

2-53. Heat Flow and Temperature / 89

2-54. Heat Transfer by Conduction / 92

2-55. Heat Transfer by Convection / 93

2-56. Heat Transfer by Radiation / 94

2-57. Electrical Heat Transfer Analogy / 96
2-58. Terrestrial Array Operating Temperatures / 98

Reliability / 98

2-59. Reliability and Failure Rates / 98

2-60. Failure Modes and Effects / 99

2-61. Reliability Models / 101

Orbital Analysis / 102

2-62. Spacecraft Motion in Orbit / 102

2-63. Simplified Orbit Theory / 102

2-64. Altitude in Elliptic Orbits / 104

2-65. Location in Space / 104

2-66. Illumination of the Orbit Plane / 106

2-67. The Sun Angle / 107

2-68. Solar Eclipses / 108

\section{Array Design 111}

Design Concepts / 111

3-1. The Design Process / 111

3-2. Design Phases / 111

3-3. Design Personnel / 112

3-4. Uncertainties and Risks / 112

3-5. Design Optimization / 112

3-6. Design Requirements, Criteria and Interfaces / 113

3-7. Policy Constraints / 115

3-8. Design Review / 116

3-9. Producibility and Cost / 117

3-10. Human Engineering / 117

Photovoltaic System Design / 117

3-11. Load Profile Development / 117

3-12. Illumination Profile Development / 119

3-13. Preliminary Array Sizing-Area Method / 123

3-14. Preliminary Array Sizing-Cell Efficiency Method / 123

3-15. Preliminary Array Sizing-Cell Power Method / 124

Detailed Array Design / 124

3-16. Detailed Array Sizing / 124

3-17. Space Array Configuration Selection / 126

3-18. Number of Required Solar Cells / 126

3-19. Array Layout / 129

3-20. Array Wiring / 130

3-21. Hot Spot Design Considerations / 131 
3-22. Designing for Reliability / 132

3-23. High Voltage Design / 132

Thermal Design / 132

3-24. Temperature Control in Space / 132

3-25. Temperature Control on Earth / 133

3-26. Decreasing Absorptance / 134

3-27. Increasing Emittance / 134

3-28. Increasing Convection / 135

3-29. Improving the Geometry / 135

3-30. Minimizing Eclipse Exit Temperatures / 136

Radiation Shielding Design / 136

3-31. Solar Cell Radiation Shielding / 136

3-32. Damage-Equivalent Fluence in Orbit / 137

3-33. Shielding Thickness Determination / 137

3-34. Procedure for 1-MeV Fluence Analysis / 140

3-35. Shielding Against Low Energy Protons / 142

3-36. Absorbed Dose in Cover and Adhesive / 144

Electromagnetic Design / 145

3-37. Electrostatic Shielding / 145

3-38. Magnetic Cleanliness / 146

3-39. Minimizing Magnetic Moments / 147

3-40. Electrostatic Charging Control / 149

\section{PART II ARRAY BUILDING BLOCKS}

\section{Solar Cells 155}

Photovoltaics / 155

$\checkmark$ 4-1. Solar Cell Devices / 155

4-2. Direct Energy Conversion / 155

4-3. Discovery of the Photovoltaic Effect / 156

4-4. History of Contemporary Silicon Cells / 156

4-5. History of Non-Silicon Cells / 159

Solar Cell Types / 160

4-6. Solar Cell Classification / 160
4-7. Classification According to Application / 160

4-8. Classification According to Materials / 161

4-9. Classification According to Construction / 163

4-10. Classification According to Optical Features / 164

4-11. Contemporary Silicon Solar Cell Types for Space Use / 165

4-12. Contemporary Silicon Solar Cells for Terrestrial Use / 165

Electrical Characteristics / 167

4-13. Solar Cell Polarity / 167

4-14. Current-Voltage Characteristics / 167

4-15. Series Resistance / 168

4-16. Shunt Resistance / 170

$\times 4-17$. Energy Conversion Efficiency / 170

4-18. Curve and Fill Factors / 171

4-19. Effects of Solar Intensity / 172

4-20. Reversible Effects of Temperature / 173

4-21. Temperature Coefficients / 173

4-22. Irreversible Temperature Effects / 178

4-23. High-Intensity, High-Temperature Operation / 178

4-24. Low-Intensity, Low-Temperature Operation / 179

4-25. Reverse Characteristics / 179

Optical Characteristics / 180

4-26. Effects of Optical Characteristics on Cell Efficiency / 180

4-27. Spectral Response Defined / 181

4-28. Spectral Response of Solar Cells / 183

Mechanical Characteristics / 184

4-29. Solar Cell Sizes and Shapes / 184

4-30. Cell Thicknesses / 185

4-31. Active Area / 186

Contacts / 187

4-32. Solar Cell Contact Types / 187

4-33. Contact Configurations / 188

4-34. Contact Strength / 189

Radiation Effects / 190 *

4-35. Solar Cell Radiation Damage / 190 
4-36. Damage-Equivalent 1-MeV Fluence / 192

4-37. Effects of Base Resistivity / 193

4-38. Low-Energy Proton Damage / 193

4-39. Radiation Damage Annealing and Output Instabilities / 195

Practical Considerations / 196

4-40. Glassed Cell Output / 196

4-41. Distribution of Parameters / 196

4-42. Handling Precautions / 196

4-43. Storage / 196

4-44. Solar Cell Space Flight Experiments / 196

4-45. Laboratory Test Data for Space Cells / 209

4-46. Radiation Test Data for Space Cells / 224

\section{Optical Elements 242}

Functions of Optical Elements / 242

5-1. Flat-Plat Optics / 242

5-2. Concentrator Optics / 242

5-3. Historical Developments / 243

Optical Energy Transfer / 245

5-4. The Optical System / 245

5-5. The Air (or Space)-To-Cover Interface / 247

5-6. The Cover-To-Cell Interface / 248

5-7. Glassing Factors / 249

5-8. Angle-of-Incidence Effects / 249

5-9. Thermal Control / 250

Covers for Space Applications / 252

5-10. Classification of Covers and Coatings / 252

5-11. Cover Materials / 252

5-12. Coatings and Filters / 255

5-13. Mechanical Characteristics / 255

5-14. Conductive Coatings / 257

5-15. Cover Adhesives / 258

5-16. Integral Organic Covers / 259

Windows for Terrestrial Applications / 259

5-17. Window Construction / 259

5-18. Window Requirements / 262

5-19. Window Materials / 263

Sunlight Concentrators / 264

5-20. Principles of Sunlight Concentration / 264

5-21. Concentrator Types / 264
6 Electrical Elements 268

Solar Cell Interconnectors / 268

6-1. Interconnector Terminology / 268

6-2. Interconnector Types / 269

6-3. Solar Cell Interconnector Design Requirements / 269

6-4. Solar Cell and Interconnector Failure Modes / 270

6-5. Historical Developments of Solar Cell Interconnectors / 271

6-6. Soldered or Welded Joints? / 273

The Interconnector Design Problem / 274

6-7. Interconnector Material Selection / 274

6-8. Interconnector Electrical Design / 275

6-9. Minimizing Thermomechanical Stress / 276

6-10. Thermomechanical Stress in Rigid Joints / 276

6-11. Stresses in Joints Due to External Forces / 279

6-12. Changes in Intercell Gap Width / 282

6-13. Loop Deformation / 283

6-14. Stresses in Interconnector Expansion Loops / 283

6-15. Stress-free Interconnector Loops / 286

6-16. Stresses in Imbeded Interconnectors and Conductors / 287

6-17. Practical Interconnector Design Considerations / 287

6-18. Stresses in Flexible Bonded Layers / 290

Interconnector Fatigue / 292

6-19. Static and Dynamic Material Stress / 292

6-20. Stress and Strain Loading / 293

6-21. Fatigue of Materials / 294

6-22. Fatigue Life of Interconnectors / 296

Diodes / 297

6-23. Diode Applications / 297

6-24. Blocking Diodes for Energy Conservation / 297

6-25. Blocking Diodes for Fault Isolation / 298 
6-26. Blocking Diode

Characteristics / 299

6-27. Shunt Diode Use / 300

6-28. Shunt Diode Characteristics / 300

6-29. Zener Diodes / 302

Wiring and Cabling / 303

6-30. Wires and Cables / 303

$6-31$. Methods of Wiring / 303

6-32. Wiring for Terrestrial Arrays / 306

6-33. Wiring for Space Arrays / 306

6-34. Wire Insulation Properties / 306

6-35. Current Carrying Capability / 307

Terminals and Connectors / 307

6-36. Wire Terminations / 307

6-37. Connectors and Terminals for Space Arrays / 308

6-38. Connectors and Terminals for Terrestrial Use / 309

6-39. Termination Design Practices / 309

7 Mechanical Elements 312

Array Mechanical Characteristics / 312

7-1. Array Design Options / 312

7-2. Array Mechanical Elements / 313

Terrestrial Flat Plate Arrays / 314

7-3. Flat Plate Modules / 314

7-4. Open Frame Supports / 317

7-5. Roof Supports / 319

7-6. Flat Plate Orientation Mechanisms / 321

Terrestrial Concentrator Arrays / 322

7-7. Linear Concentrator Modules / 322

7-8. Axial Concentrator Modules / 325

7-9. Mirror Field Systems / 327

Space Arrays / 327

7-10. Space Array Overview / 327

7-11. Rigid Honeycomb Panels / 330

7-12. Honeycomb Panels With Stiffeners / 332

7-13. Flexible Substrates With Rigid Frames / 336

7-14. Flexible Fold-Up Blankets / 337

7-15. Flexible Roll-Up Blankets / 339

7-16. Hybrid Arrays / 342

7-17. Other Developments / 343
Deployment Mechanisms / 346

7-18. Deployable Booms / 346

7-19. Spring/Actuator Deployment Concepts / 351

Orientation Drives / 359

7-20. Orientation Mechanisms / 359

7-21. Stepping Drive Example / 360

7-22. Continuous Drive Example / 361

\section{PART III SUPPORT DATA 366}

8 Fabrication and Test 367

8-1. Soldering / 367

8-2. Welding / 369

8-3. Thermocompression Joining / 371

8-4. Ultrasonic Joining / 371

8-5. Electrical Degradation Due to Joining / 372

8-6. Adhesive Bonding / 372

Assembly Process Control / 373

8-7. Metal Joining Control / 373

8-8. Nondestructive Testing (NDT) / 373

8-9. Adhesive Bonding Control / 375

8-10. Visual Inspection / 375

8-11. Workmanship Criteria / 375

Photovoltaic Testing / 376

8-12. History of Solar CellTesting / 376

8-13. Standard Solar Cells / 379

8-14. Light Sources For Solar CellTesting / 382

8-15. Solar Simulators / 383

8-16. Solar Cell Output Measurements / 387

8-17. Array Output Measurements / 388

8-18. Standard Test Conditions / 388

8-19. Effects of Lead and Contact Resistances / 389

8-20. Three Types of Solar Cell $I-V$ Curves / 389

8-21. Measurement of Solar Cell Series Resistance / 390

8-22. Dark Forward-Testing / 391

8-23. Insulation Resistance and Voltage Breakdown / 393

Thermo-optical Measurements / 394

8-24. Measurement of Spectral Distribution and Spectral Response / 394 
8-25. Determination of Solar Absorptance / 394

8-26. Determination of Hemispherical Emittance / 394

8-27. Measurement of Spectral Reflectance / 395

8-28. Measurement of Total Reflectance / 396

Environmental Testing / 396

8-29. Particle Radiation Testing / 396

8-30. Ultraviolet RadiationTesting / 397

8-31. Far Ultraviolet Testing / 398

8-32. Combined EnvironmentsTesting / 398

8-33. Temperature CyclingTesting / 402

Significance of Test Data / 403

8-34. Errors / 403

8-35. Uncertainties / 403

8-36. Uncertainties in Inspection / 404

8-37. Significance of Sample Size / 405

\section{Environments and Their Effects 408}

9-1. The Solar Cell Array Environment / 408

Solar Energy / 408

9-2. The Sun / 408

9-3. The Solar Constant / 408

9-4. Albedo / 410

9-5. Solar Radiation Pressure / 410

9-6. Terrestrial Sunshine / 412

9-7. Ultraviolet Radiation / 415

Terrestrial Environments / 416

9-8. Temperature-Terrestrial / 416

9-9. Humidity / 420

9-10. Precipitation / 421

9-11. Wind / 421

9-12. Sand, Dust, Dirt / 422

9-13. Earthquakes / 422

9-14. Gravity / 423

9-15. The Atmosphere / 423

9-16. Atmospheric Electricity / 424

9-17. Corrosion / 424

9-18. Ozone / 426

9-19. Fungi and Bacteria / 426

9-20. Salt Spray / 427

9-21. Biotic Elements / 427
9-22. Vandalism / 427

Handling and Transportation / 427

9-23. Handling and Assembly / 427

9-24. Vibration and Acoustic Noise in Transportation / 428

9-25. Mechanical Shock in Transportation / 428

9-26. Storage / 428

9-27. Pressure/Altitude in Transportation / 428

Launch and Flight of Space Arrays / 428

9-28. Dynamic Forces During Launch and Flight / 428

9-29. Acceleration / 429

9-30. Shock (Mechanical) / 429

9-31. Vibration / 430

9-32. Acoustic Field / 433

The Space Environment / 433

9-33. The Solar System / 433

9-34. The Space Vacuum / 435

9-35. Meteoroids / 437

9-36. Deposits / 438

9-37. Gravity in Space / 438

9-38. Time in Space / 438

9-39. Magnetic Fields / 439

9-40. Temperature in Space / 440

9-41. Solar Cell Arrays in Orbit / 441

9-42. Solar Eclipses / 441

The Radiation Environment in Space / 443

9-43. Radiation Terms / 443

9-44. Space Radiation and its Effects / 446

9-45. Radiation in Interplanetary Space / 448

9-46. Solar Flares / 448

9-47. Radiation Near Earth / 453

9-48. Radiation At Synchronous Altitude / 456

9-49. Geomagnetic Substorms / 457

\section{Material Properties 460}

10-1. Where to Find the Data / 460

10-2. Material Properties and the Designer / 460

General Characteristics / 460

10-3. Characteristics of Metals / 460

10-4. Characteristics of Nonmetals / 463 
10-5. Density, Mass and Weight / 466

10-6. Centroids, Moments of Inertia and Radii of Gyration / 466

Mechanical Properties / 467

10-7. Stress, Strain, and Strength / 467

10-8. Stiffness and Bending Stress / 473

10-9. Mechanical Properties as Function of Temperature / 474

10-10. Elongation and Reduction in Area / 475

10-11. Fatigue Life / 476

10-12. Mechanical Properties of Elastomers / 476

10-13. Outgassing and Weight Loss / 477

Thermal Properties / 478

10-14. Thermal Expansion / 478
10-15. Specific Heat and Heat Conductance / 490

Electromagnetic Properties / 491

10-16. Electrical Properties of Conductors / 491

10-17. Electrical Properties of Dielectrics / 492

10-18. Magnetic Properties / 495

10-19. Thermal Emittance / 498

Appendices

Appendix A Mathematics / 503

Appendix B Insolance Tables / 507

Appendix C Physical Constants / 522

Appendix D Conversion Factors and Formulas / 527

Appendix E $1 \mathrm{MeV}$ Fluence

Tables / 534

Index / 539 


\section{Solar Cell \\ Array Design Handbook}

The Principles and Technology of Photovoltaic Energy Conversion 